\title{
Parathyroid Cyst
}

National Cancer Institute

\section{Source}

National Cancer Institute. Parathyroid Cyst. NCI Thesaurus. Code C4384.

An epithelium-lined, fluid-filled cyst containing parathyroid hormone that is usually located in an inferior parathyroid gland, but may be found in other locations in the neck or mediastinum. 